\title{
Limits to the Aerosol Indirect Radiative Effect Derived from Observations of Ship Tracks
}

\author{
James A. Coakley, Jr. and Christopher D. Walsh \\ College of Oceanic and Atmospheric Sciences \\ Oregon State University \\ Corvallis, OR 97331-5503
}

(15 June 2001)

Corresponding Author: James A. Coakley, Jr.

College of Oceanic and Atmospheric Sciences

Ocean Admin 104

Oregon State University

Corvallis, OR 97331-5503

PHONE: (541) 737-5686 FAX: (541) 737-2540

coakley@oce.orst.edu 


\begin{abstract}
A B S T R A C T
1-km Advanced Very High Resolution Radiometer (AVHRR) observations of the effects of ships on low-level clouds off the west coast of the U.S. are used to derive limits for the degree to which clouds might be altered by increases in anthropogenic aerosols. As ships pass beneath low-level clouds, particles from their plumes serve as condensation nuclei around which new cloud droplets form. The increased droplet concentrations lead to a decrease in droplet sizes. The change in sizes is manifested as an increase in the reflected sunlight observed at $3.7 \mu \mathrm{m}$ in satellite imagery data. Images at $3.7 \mu \mathrm{m}$ are used in a semi-automated procedure for identifying polluted portions of clouds and distinguishing them from the nearby unaffected portions. Radiances at $0.64,3.7$, and $11 \mu \mathrm{m}$ are used to determine visible optical depths, droplet effective radii, and cloud emission temperatures for both the polluted and unpolluted portions. The analysis of several hundred 30-km segments of ship tracks reveals that changes in visible optical depths are about half the values expected given the changes observed for the droplet radii and assuming cloud liquid water amount remains constant. Simple radiative transfer calculations indicate that the shortfall in the optical depth change is unlikely to be due solely to the absorption by the polluting particles. It is likely that polluted clouds lose liquid water. The equivalent loss is approximately $15-20 \%$ of the initial cloud liquid water.
\end{abstract}




\section{Introduction}

The effect of particle pollution on the numbers and sizes of droplets in low-level clouds and the consequent effects on cloud lifetimes and the amount of sunlight reflected by clouds ranks among the largest sources of uncertainty in determining man's impact on climate. This effect is referred to as the "indirect effect" or the "Twomey effect." In its simplest form, higher concentrations of aerosols provide higher concentrations of cloud condensation nuclei $(\mathrm{CCN})$ and more cloud droplets. Because droplet formation is rapid with respect to the typical lifetime of clouds, the cloud liquid water concentration, which is governed primarily by the thermodynamics of the environment in which the cloud resides, remains relatively constant. Consequently, with the added CCN, there are more droplets, but the droplets are smaller. As Twomey (1977) noted, such a change would lead to an increase in cloud albedos and only in the case of optically thick clouds and strongly absorbing particles would the increase in CCN lead to a decrease in cloud albedo.

In addition to the change in albedo, the changes in droplet numbers and sizes bring about changes in the interactions between the cloud and its environment. Albrecht (1989) noted that the smaller droplets in polluted clouds might suppress the formation of drizzle, thereby increasing cloud liquid water concentrations and cloud lifetimes, and thus the sunlight reflected by clouds. In addition, Pincus and Baker (1994) used a mixed layer model to show that the changes in droplet numbers and sizes cause the cloud to thicken. The cloud tops rise to higher altitudes so that cloud liquid water is increased, thereby enhancing cloud reflectivities. 
In recent years, simulations of the aerosol indirect effect in general circulation models indicate that the globally averaged reflected sunlight might increase anywhere from $0.2 \mathrm{Wm}^{-2}$ to $4.8 \mathrm{Wm}^{-2}$ (Lohmann and Feichter 1997, Rotstayn 1999, Lohmann et al. 2000). About half the enhancement in the simulations is due to changes in cloud albedos, when the cloud liquid water is kept constant, and half is due to changes in cloud liquid water and cloud fraction in response to changes in precipitation and in the thermodynamic state of the model atmosphere. Thus, the indirect effect of aerosols could be of little consequence, or it could be so large as to mask the radiative forcing due to the buildup of the greenhouse gases since 1850, which stands at about $2 \mathrm{Wm}^{-2}$. As Hansen et al. (1997) suggest, assessments of climate change cannot possibly be reliable when faced with such uncertainties in the radiative forcing.

Low-level clouds affected by ships off the west coast of the U.S. offer a wealth of opportunities to assess the response of clouds to increased particulate pollution and thereby provide a means for bracketing the possible outcomes of increased particle pollution. Ship tracks were first used to verify that reflectivities of polluted clouds were indeed higher, as Twomey had suggested, despite the likelihood of absorbing particles in ship exhaust (Coakley et al. 1987). Ship exhaust and the ship tracks produced in low-level clouds were extensively studied in the Monterey Area Ship Track (MAST) Experiment which was conducted in June 1994 (Durkee et al. 2000 and the other papers in the special issue devoted to MAST). Ship tracks have been used to demonstrate that polluted clouds retain cloud liquid water, as Albrecht (1989) suggested, thereby enhancing the indirect effect (Radke et al. 1989; Platnick and Twomey, 1994; Taylor et al. 2000), and they have also been used to show that polluted clouds have less liquid water than their nearby unpolluted counterparts (Platnick et al. 2000), thereby reducing the indirect effect when 
compared to the changes expected if liquid water remained constant as Twomey originally proposed. Studies with a mixed layer model of stratus also indicate that while drizzle is suppressed and liquid water concentrations increase in the upper levels of the cloud, the smaller droplets in polluted clouds evaporate more readily, giving rise to a decrease in column cloud liquid water (Ackerman et al. 1995). Using aircraft observations of droplet size distributions from the MAST experiment, Ackerman et al. (2000) found that the average concentration of liquid water in 69 ship tracks was lower than in surrounding clouds. Nevertheless, albedos were observed for 17 ship tracks, and the albedos for the polluted clouds were higher than those of the surrounding clouds suggesting that for these tracks, cloud thickness had increased to compensate for the decrease in liquid water concentrations. While there was considerable spread in the observations, the albedo changes for the 17 ship tracks were statistically consistent with fixed column liquid water amounts.

Here, 1-km Advanced Very High Resolution Radiometer (AVHRR) observations of shiptracks in low-level clouds are used to determine how clouds are altered by increases in anthropogenic aerosols. Cloud optical depths at visible wavelengths, cloud emission temperatures, and droplet effective radii retrieved from AVHRR radiances are used to determine whether polluted clouds contain more or less liquid water than nearby unpolluted clouds. This work supersedes previous studies in that many more ship tracks are studied thereby increasing the level of confidence in the changes produced by the pollution in the face of the large natural variability exhibited by clouds. In addition, comparisons are restricted to 1-km fields of view that are overcast by layered cloud systems. The retrieval of cloud properties undertaken here are, as all such retrievals, limited by the validity of plane-parallel radiative transfer theory. While such 
retrievals are far from ideal, (Loeb and Coakley, 1998), they are nonetheless, best suited for extensive layered systems, like those studied here.

\section{Data and Method}

NOAA-12 (morning) and NOAA-14 (afternoon) 1-km AVHRR High Resolution Picture Transmission (HRPT) data were collected by the Oregon Earth Watch Facility for July 1999. The facility collects data for passes which cover the west coast of the U.S. from Baja California to British Columbia. The facility began operation on 1 July 1999. Passes were collected on all days. Each pass was visually inspected for ship tracks, and as described below, the position of each track was logged by hand. The number of tracks logged and the number which yielded results suitable for comparison are given in Table 1. Similar numbers of tracks have been logged for the NOAA-11 and NOAA-12 observations collected for the June 1994 MAST experiment. Analysis

of the MAST data is continuing. The additional data will be used to investigate the sensitivity of the findings reported here to viewing geometry and the distance along the track from the ship. For July, solar zenith angles for the morning satellite, NOAA-12, are such that only about half the scan is in sunlight; the remainder is in darkness. Consequently, the retrieval of cloud properties from the NOAA-12 observations were severely handicapped and the retrievals used in this study were therefore limited to the NOAA-14 AVHRR observations.

The retrieval of cloud properties requires calibrated radiances. For radiances at $0.64-\mu \mathrm{m}$ and $0.84-\mu \mathrm{m}$, reflectances for the extensive ice sheets of Greenland and Antarctica were used 
(Tahnk and Coakley, 2000ab). For radiances at 3.7 and $11 \mu \mathrm{m}$, the gain and off-set calibration procedure described by Lauritsen et al. (1979) was used.

The retrieval of cloud properties and the comparison of properties for clouds affected by ships with those of nearby clouds that were unaffected involved three steps: 1) each pixel was identified as being either cloud-free, partly cloud covered, or overcast by optically thick, layered clouds; 2) surface temperatures were then retrieved for the cloud-free pixels and cloud properties were retrieved for pixels overcast by layered clouds, and 3) overcast pixels that were affected by ships were identified and nearby pixels overcast by unaffected clouds were selected at random for comparison. An automated scheme for identifying clouds contaminated by ships and distinguishing clouds in the vicinity that remained uncontaminated, was applied only to the pixels found to be overcast by optically thick, low-level clouds, and for which the retrieval scheme succeeded in determining the visible optical depth, cloud emission temperature, and effective droplet radius from the observed radiances.

\subsection{Scene Identification}

For the identification of cloud-free, partly cloudy, and overcast fields of view, the following steps were used. Fields of view were identified as cloud-free if they exhibited locally uniform reflected sunlight and thermal emission on scales of $\sim 4 \mathrm{~km}(4 \times 4$ pixel arrays $)$ for the 1-km AVHRR HRPT observations. Reflected sunlight was taken to be uniform if the standard deviation of the $0.64-\mu \mathrm{m}$ reflectance for a pixel array was less than 0.004 . Emission was taken to be uniform if the standard deviation of the $11-\mu \mathrm{m}$ radiances for a pixel array was less than 
$0.5 \mathrm{mWm}^{-2} \mathrm{sr}^{-1} \mathrm{~cm}$, equivalent to a standard deviation of about $0.4 \mathrm{~K}$ for midlatitude sea surface temperatures. Away from regions of sun glint, cloud-free ocean scenes were required to have a ratio of the near infrared $(0.84 \mu \mathrm{m}$, AVHRR Channel 2$)$ reflectance to visible $(0.64 \mu \mathrm{m}, \mathrm{AVHRR}$ Channel 1) reflectance that was less than 0.85 for the NOAA-14 AVHRR and 0.75 for the NOAA-12 AVHRR. The smaller ratio for the NOAA-12 AVHRR is due to the larger solar zenith angles encountered by the NOAA- 12 observations. Overcast pixels produce values of near unity for the near infrared to visible reflectance ratio while pixels with vegetated land produce values greater than unity (Saunders and Kriebel, 1988). Here, sunlight was taken to be outside of the sun glint region if the light was reflected at angles greater than $30^{\circ}$ from the angle for specular reflection from a flat surface.

To complete the identification of cloud-free, partly cloudy, and overcast pixels, each pass was divided into regions $\sim 250-\mathrm{km}$ on a side. Within such a region, pixels satisfying the conditions of locally uniform emission and reflection and having suitably small values of the near infrared to visible reflectance ratios were taken to be candidates for being cloud-free. The distributions of $0.64-\mu \mathrm{m}$ reflectance and $11-\mu \mathrm{m}$ emission for these candidate cloud-free pixels were used to set thresholds for the $0.64-\mu \mathrm{m}$ reflectance and $11-\mu \mathrm{m}$ emission associated with cloud-free pixels. For the candidate pixels, the $5^{\text {th }}$ percentile of the $11-\mu \mathrm{m}$ radiances was taken to be a lower threshold for the emitted radiances and the $95^{\text {th }}$ percentile of the $0.64-\mu \mathrm{m}$ reflectances was taken to be an upper threshold for the reflectances of cloud-free pixels. These thresholds were applied to the candidate cloud-free pixels within the $\sim 150-\mathrm{km}$ subregion centered within the larger $\sim 250-\mathrm{km}$ region. Emission by cloud-free pixels was used to determine the sea surface temperature, which in turn, was used to calculate thermal emission incident on the cloud from below. When no 
cloud-free pixels were found within a $\sim 150-\mathrm{km}$ subregion being studied, a climatology of sea surface temperatures was used to calculate the emission incident on the bottom of the cloud.

Fields of view not identified as being cloud-free but which exhibited locally uniform emission at $11 \mu \mathrm{m}$ were taken to be candidates for being overcast by layered cloud systems. As with the cloud-free pixels, pixel arrays were taken to exhibit locally uniform emission if the standard deviation of the $11-\mu \mathrm{m}$ radiances was less than $0.5 \mathrm{mWm}^{-2} \mathrm{sr}^{-1} \mathrm{~cm}$, equivalent to a standard deviation of about $0.4 \mathrm{~K}$ for emission by opaque clouds at $1 \mathrm{~km}$ in a midlatitude summertime atmosphere. Pixels that exhibited neither locally uniform reflectances nor locally uniform emitted radiances were presumed to be partly cloud covered. The $50^{\text {th }}$ percentile of the $0.64-\mu \mathrm{m}$ reflectances for the partly cloudy pixels was used as a minimum reflectance for pixels overcast by optically thick clouds. This threshold was then applied to the fields of view exhibiting locally uniform emission that were not cloud-free in order to identify fields of view that were overcast by optically thick, layered cloud systems. The application of this threshold eliminates fields of view which have small amounts of low-level cloud, and thus satisfy the condition of locally uniform $11-\mu \mathrm{m}$ emission expected for overcast fields of view. Of course, the application also eliminates fields of view which may be overcast by optically thin cloud. As will be shown later, the retrieved $0.64-\mu \mathrm{m}$ optical depths ranged from about 4 to 30 .

The identification of pixels identified as either cloud-free or overcast by optically thick clouds from a single layer was repeated region by region and subregion by subregion until all fields of view observing ocean scenes within the overpass were identified. The regions and subregions were overlapped to ensure that all pixels were identified. 


\subsection{Cloud Property Retrievals}

For pixels identified as being overcast by single-layered, low-level, water clouds, radiances at $0.64,3.7$, and $11 \mu \mathrm{m}$ from $1-\mathrm{km}$ AVHRR data were used to determine $0.64-\mu \mathrm{m}$ optical depths, cloud emission temperatures, and effective droplet radii. The retrieval scheme is similar to others (e.g., Han et al. 1994) in that for the viewing geometry of the observations, optical depth, cloud emission temperature, and effective droplet radius are adjusted until radiances at 0.64, 3.7, and $11 \mu \mathrm{m}$ calculated with a plane-parallel radiative transfer model match those observed. DISORT (Stamnes et al. 1988) was used to calculate the reflectances for solar radiation and the diffuse reflection and transmission functions for thermal emission. The cloud was placed at an altitude of $1 \mathrm{~km}$ and treated as an infinitesimally thin, but optically finite, layer. This layer was imbedded in a scattering, absorbing, and emitting atmosphere. A correlated-k model (Kratz, 1995) was used to allow for absorption and emission by $\mathrm{O}_{2}, \mathrm{O}_{3}, \mathrm{H}_{2} \mathrm{O}, \mathrm{N}_{2} \mathrm{O}$, and $\mathrm{CH}_{4}$. The Rayleigh optical depth at $0.64 \mu \mathrm{m}$ was taken to be 0.053 , consistent with the value given by Pendorf (1957). No Rayleigh scattering was included in the calculations of radiances at 3.7 and $11 \mu \mathrm{m}$. Scattering and absorption by aerosols was not included in the calculations. The ocean surface was taken to be Lambertian and the albedo set to zero at the three wavelengths. A midlatitude summer climatological profile was used for the vertical distribution of temperature and water vapor.

For reflected sunlight, reflectances were taken directly from the results of DISORT. Reflectances were precomputed for $160.64-\mu \mathrm{m}$ optical depths ranging from 1 to 64 . A 
lognormal distribution was used for droplet radii and calculations were performed for distributions having mode radii that ranged from 2 to $40 \mu \mathrm{m}$. The effective variance for the droplet size distribution was 0.193 . For this value of the effective variance, the effective radius is 1.55 times the mode radius. Reflectances were calculated for every $10^{\circ}$ in solar zenith angle from $0^{\circ}$ to $80^{\circ}$, for every 0.1 in the cosine of the satellite zenith angle from 0.3 to 1.0 , and for every $20^{\circ}$ in the relative azimuth angle from $0^{\circ}$ to $180^{\circ}$. The precomputed values were linearly interpolated to obtain radiances for a particular $0.64-\mu \mathrm{m}$ optical depth, droplet effective radius, and sun-targetsatellite viewing geometry.

Emitted radiances were taken to be given by

$$
\begin{gathered}
I^{+}(\mu, \infty)=\left[\varepsilon_{C}(\mu) B\left(T_{C}\right)+\int_{0}^{1} d \mu^{\prime} r_{C}\left(\mu, \mu^{\prime}\right) I^{-}\left(\mu^{\prime}, z_{C}\right)+\int_{0}^{1} d \mu^{\prime} t_{C}\left(\mu, \mu^{\prime}\right) I^{+}\left(\mu^{\prime}, z_{C}\right)\right] t_{A}\left(z_{C}, \infty, \mu\right) \\
+\int_{0}^{\infty} B\left(z^{\prime}\right) d t_{A}\left(z^{\prime}, \infty, \mu\right) .
\end{gathered}
$$

The first term in (1) is the contribution to the observed radiance, $I^{+}(\mu, \infty)$, due to radiation emitted by the cloud and transmitted through the atmosphere to the satellite sensor. $\varepsilon_{C}(\mu)$ is the emissivity of the cloud for radiation emitted with a zenith angle for which the cosine is $\mu$. The emissivity depends on the cloud optical depth and droplet effective radius. The cloud is at the temperature $T_{C}$, which is taken to be the cloud emission temperature, and $B\left(T_{C}\right)$ is the Planck function evaluated at the cloud emission temperature. The cloud emission temperature is free to take any value. It is not tied to the temperature of the atmosphere at $1 \mathrm{~km}$, the level of the cloud. 
The altitude of the cloud determines the opacity of the atmosphere and the emission by atmospheric gases above and below the cloud. $t_{A}\left(z_{C}, \infty, \mu\right)$ is the transmission of the atmosphere from the level of the cloud, $z_{C}$, to the top of the atmosphere for the zenith angle for which the cosine is $\mu$. Here, $z_{C}=1 \mathrm{~km}$. The second term is the contribution from the downward radiation incident at the top of the cloud, $I^{-}\left(\mu^{\prime}, z_{C}\right)$, propagating in the direction for which the cosine of the zenith angle is $\mu^{\prime}$, that is reflected by the cloud and transmitted through the atmosphere to the satellite sensor. The downward radiation incident on the top of the cloud is due to emission by atmospheric gases above the cloud. $r_{C}\left(\mu, \mu^{\prime}\right)$ is the reflection function for radiation incident on the cloud propagating in the direction for which the zenith angle is $\mu^{\prime}$ and reflected in the direction for which the zenith angle is $\mu$. The reflection function, like the emissivity, depends on the cloud optical depth and droplet effective radius. The third term is the contribution from radiation incident at the bottom of the cloud, $I^{+}\left(\mu^{\prime}, z_{C}\right)$, transmitted through the cloud, and then transmitted through the atmosphere to the satellite sensor. Radiation incident at the bottom of the cloud is due to emission by the surface which is transmitted through the subcloud atmospheric layer and emission by the atmospheric layer beneath the cloud. $t_{C}\left(\mu, \mu^{\prime}\right)$ is the transmission function for the cloud. It is analogous to the reflection function. The final term is the contribution due to emission by atmospheric gases above the cloud. $B\left(z^{\prime}\right)$ is the Planck function at the temperature of the atmospheric level $z^{\prime}$. The various terms in (1) were precomputed assuming unit values for the cloud emissivity, reflectivity, and transmissivity. In the course of the retrieval, as different values of the cloud optical depth and droplet effective radius were tried in order to obtain agreement between the observed and calculated radiances, the corresponding values of the emissivity, reflectivity, and transmissivity were multiplied times the appropriate, 
precomputed term to obtain the desired contribution to the emitted radiance. Values for the reflection and transmission functions were precomputed using DISORT for the ranges of optical depths and droplet effective radii noted earlier. The emissivity, in turn, was derived from the reflection and transmission functions.

For pixels found to be overcast by low-level, optically thick clouds, the $0.64-\mu \mathrm{m}$ optical depth, the cloud emission temperature, and the effective droplet radius were adjusted iteratively until successive changes in the optical depth were less than 0.5 , changes in the cloud emission temperature were less than $0.5 \mathrm{~K}$ and changes in the droplet effective radius were less than $0.2 \mu \mathrm{m}$. Typically, the radiances computed using the retrieved optical depths, emission temperatures, and droplet effective radii agreed with the observed radiances to within a few tenths of a percent.

The retrieved cloud properties represent indices of the physical properties averaged over the domain of the 1-km fields of view. Reports of comparisons between the retrieved properties and in situ measurements of the corresponding physical counterparts are rare (Nakajima et al., 1991, Platnick and Valero, 1995; Nakajima and Nakajima, 1995, Kuji et al. 2000). Nakajima et al. report reasonable agreement between observed and retrieved estimates of visible optical depths, but the droplet effective radii retrieved using reflectances at $2.1-\mu \mathrm{m}$ were $1-2 \mu \mathrm{m}$ larger than the in situ measurements. Retrievals using AVHRR radiances, like those used here, produced somewhat better agreement (Nakajima and Nakajima, 1995 and Kuji et al. 2000). The retrieved properties obtained with the current scheme are likely to agree with their corresponding physical counterparts with about the same level of accuracy, 1-2 units in the $0.64-\mu \mathrm{m}$ optical 
depth for clouds with optical depths $\sim 10$, and 1-2 $\mu \mathrm{m}$ in droplet effective radius. For identical viewing geometries, 0.64 and $3.7-\mu \mathrm{m}$ reflected radiances calculated using the current scheme indicate that for clouds having droplets with effective radii between 5 and $15 \mu \mathrm{m}$, the retrieved optical depths should be within 1 unit and the effective droplet radii should be within $2 \mu \mathrm{m}$ of those derived using the schemes developed by Nakajima and Nakajima (1995) and by Kuji et al. (2000).

In order to determine the sensitivity of the retrieved properties to the temperatures and moisture profiles used to calculate the radiances, retrievals were also performed using 1) average temperature and humidity profiles constructed from radiosonde data collected off the California coast during the June 1994 MAST experiment and 2) tropical marine climatological profiles. Average droplet effective radii were $1.2 \mu \mathrm{m}$ larger for the MAST profiles when compared with those obtained with the midlatitude summer profiles which in turn were $0.7 \mu \mathrm{m}$ larger than those obtained with the tropical marine profiles. These differences are attributed to differences in absorption by water vapor at $3.7 \mu \mathrm{m}$. Atmospheric corrections for the tropical profiles are larger than those for the midlatitude summer profiles, which in turn are larger than those for the MAST profiles. Owing to differences in ozone concentrations, average $0.64-\mu \mathrm{m}$ optical depths were 0.2 larger for the tropical marine profiles than for the midlatitude summer and MAST profiles. When determining the effects due to ships on the clouds, differences for the changes in droplet effective radii and optical depths were smaller for the different profiles. The average differences were less than $0.06 \mu \mathrm{m}$ for changes in the droplet effective radii and less than 0.1 for changes in the optical depths. Consequently, assessments of the effects of ships on the overlying clouds were relatively insensitive to the meteorological profiles used to calculate the reflected and emitted radiances. 
Finally, Ackerman et al. (2000) noted that a substantial part of the reduction in cloud liquid water observed for ship tracks was due to increased variance in the droplet size distributions for the polluted clouds. The aircraft observations indicated an average increase of about $30 \%$ in the effective variance. Here the variance of the droplet size distribution was held fixed. A sensitivity study was performed in which droplet size distributions had droplet effective radii of $10 \mu \mathrm{m}$ but effective variances half and twice the standard value. 0.64 and $3.7-\mu \mathrm{m}$ reflectances were calculated for clouds with the modified droplet size distributions and these reflectances were used to retrieve the $0.64-\mu \mathrm{m}$ optical depth and droplet effective radius based on the reflectances obtained using the standard value of the effective variance. The shift in reflectances resulted in a $0.7-\mu \mathrm{m}$ shift in the retrieved droplet effective radius and a shift in the $0.64-\mu \mathrm{m}$ optical depth of 0.2 for clouds with optical depths of 10 . As will be shown later, changes in the droplet effective radii and $0.64-\mu \mathrm{m}$ optical depths were several times as large as the changes obtained by halving or doubling the effective variance. Consequently, it is unlikely that shifts in the variance of the droplet size distribution, like that derived from aircraft observations, would substantially alter the findings presented here.

\subsection{Identification of Ship Tracks}

A semi-automated routine was used to identify portions of the cloud polluted by underlying ships and to separate those portions from nearby clouds which were unpolluted. The first step in the identification was done by hand. For a given ship track, the relative scan spot and scan line numbers within the pass were logged along the track. The number of points logged 
varied from as few as two, to as many as a half dozen. The number was governed by the length and number of bends in the track. The first point logged was the position thought to be, based on the appearance of the track, nearest the ship. The point nearest the ship is referred to as the head of the track. Only tracks with a clearly discernible head were analyzed. Knowledge of the position of the head facilitates using distance along the track as a measure of the time over which the track has evolved. The requirement of a clearly discernible head also reduces the identification as a ship track, track-like features in the imagery which are thought to be due to the effects of gravity waves propagating in the boundary layer.

An example of points logged for one ship track is shown in Figure 1. The figure shows images created from reflectances at $0.64 \mu \mathrm{m}$ and radiances at $3.7 \mu \mathrm{m}$ for a small portion of a pass. As will be discussed below, the logged locations were not required to fall precisely on the track, and in the case shown, the head of the track was clearly missed. The logged locations were used to establish the domain surrounding the track from which pixels with polluted clouds and their uncontaminated counterparts were drawn. The dark boundaries surrounding the tracks in Fig. 1 illustrate the domains associated with several tracks. In the example shown, the domain was taken to be approximately $30 \mathrm{~km}$ on either side of the track.

Pixels comprising the ship track were identified through the following steps: First, starting with the head, tracks were divided into approximately $30 \mathrm{~km}$ segments along the length of the track. Changes in optical depths and droplet radii for the polluted clouds were derived from the corresponding averages of the contaminated and uncontaminated clouds within each 30-km segment. By averaging the retrieved cloud properties, effects due to the large pixel-scale 
variability in optical depth and droplet effective radius are reduced. In addition, as was noted earlier, dividing the track into segments allows for studies of the change in the indirect effect with time, because segments at a distance from the head of the track could be presumed to have evolved for greater periods than those near the head.

In order to identify the contaminated clouds, for each track segment, overcast pixels were identified as candidates for being contaminated if they had $3.7-\mu \mathrm{m}$ radiances greater than the $90^{\text {th }}$ percentile of the radiances for all overcast pixels falling within the segment and the domain on either side of the track. Of these pixels, only those which were contiguous with at least 16 other pixels also having $3.7-\mu \mathrm{m}$ radiances that exceeded the $90^{\text {th }}$ percentile were kept. For the selected pixels, the center of mass and principal axis of the moment of inertia were calculated. The center of mass had to be within $10 \mathrm{~km}$ of the line joining the nearest logged points. The principal axis of the moment of inertia had to be aligned so that the angle between the principal moment and the scan spot to scan line slope for the line joining the logged points was smaller than $15^{\circ}$.

Once the locations of the polluted pixels were determined, nearby overcast pixels that fell within the domain of the track were randomly searched to obtain an equal number of pixels overcast by uncontaminated clouds. The pixels that were selected had to be at least $10 \mathrm{~km}$ from the location of the track, as determined by straight lines joining the logged points. The highlighted pixels in Fig. 1 show the portions of the cloud identified as being polluted by the ship and the randomly selected pixels overcast by clouds in the vicinity of the track that served as uncontaminated controls. 
Average values of the optical depths, cloud emission temperatures, and droplet effective radii for the pixels overcast by polluted clouds were compared with the corresponding averages for the uncontaminated clouds within each track segment. A single segment is outlined in Fig. 1. As the figure illustrates, not all segments yielded contaminated and uncontaminated cloud properties for comparison. For a segment to be used in the comparison, there had to be at least 50 pixels identified as overcast by contaminated clouds. In addition, the number of pixels overcast by uncontaminated clouds on either side of the track had to equal the number of overcast pixels that comprised the ship track. As mentioned earlier, pixels were not selected for comparison, or for that mater, for the retrieval of cloud properties, if they were identified as being partly cloud covered. In addition, if the surrounding region lacked overcast pixels sufficient in number to match those identified as being overcast by polluted clouds, no comparisons were made. For example, large numbers of pixels containing broken cloud prevented comparisons near the head and tail of the track shown in Fig. 1. Also, in its configuration for this study, the automated scheme for identifying ship tracks avoided complex configurations such as track crossings, and in the case of multiple tracks, as illustrated in Fig. 1, the scheme was designed to identify only one of the tracks at a time.

As a final step in the analysis, the identification of contaminated and uncontaminated pixels by the automated scheme were examined visually to ensure that the scheme worked properly, at least as perceived in images like that shown in Fig. 1. The automated routine failed occasionally, particularly for complex scenes in which several tracks crossed, or in which adjacent tracks were so close that pixels identified as unpolluted for the track being analyzed fell on nearby tracks and were thus, actually polluted. For such cases, the results were rejected and not included in 
subsequent analyses. Table 1 shows the number of tracks that provided segments in which comparisons were possible and the number of segments that yielded comparisons.

\section{Results}

Figure 2 shows the $0.64-\mu \mathrm{m}$ reflectances and $3.7-\mu \mathrm{m}$ radiances and the corresponding $0.64-\mu \mathrm{m}$ optical depths and droplet effective radii associated with the $30-\mathrm{km}$ segment highlighted in Fig. 1. The results illustrate one of the difficulties encountered in detecting the aerosol indirect effect. Figure 2 shows that the change in $3.7-\mu \mathrm{m}$ radiances caused by the ship are typically larger than, or at least comparable to, the pixel-scale variability observed for these radiances. This result simply reflects the observation that ship tracks are readily detected in images constructed from 3.7- $\mu \mathrm{m}$ radiances. On the other hand, the change in $0.64-\mu \mathrm{m}$ reflectances is small compared to the pixel-scale variability in the reflectances. As a result, ship tracks are difficult to detect in visible images except, of course, when the track resides in an otherwise cloud-free region. The results in the figure illustrate, as discussed by Platnick et al. (2000), that ship tracks are easier to detect through changes in the $3.7-\mu \mathrm{m}$ radiance and droplet radius than through changes in the $0.64-\mu \mathrm{m}$ reflectance and optical depth.

The consequences of pixel-scalel variability in cloud properties are illustrated further in

Figure 3. The figure shows the pixel-scale values of the optical depths, droplet effective radii, and cloud-emission temperatures obtained for the segment of the track used to produce the results in Fig. 2. The figure shows typical relationships between visible optical depths, droplet effective 
radii, and emission temperatures. For both the polluted $(\Delta)$ and the uncontaminated control clouds $(\times)$, the visible optical depth increases with decreasing cloud emission temperature. Likewise, for the uncontaminated clouds, droplet effective radius increases with increasing visible optical depth. These relationships may reflect the growth of droplet radius with cloud geometrical thickness and the growth of optical depth with both geometrical thickness and with increasing cloud droplet radius when cloud droplet number remains constant. For the case shown in Fig. 3, as is often the case, the change in optical depths between the control and polluted clouds is barely noticeable given the wide range of optical depths exhibited by both the control and polluted clouds. Since the optical depth is proportional to the amount of cloud liquid water and inversely proportional to the droplet effective radius, if the amount of cloud liquid water were to remain constant as the cloud responds to the additional particles, then the change in the optical depths and droplet radii would be related by

$$
\frac{\Delta \tau}{\tau}=-\frac{\Delta R_{e}}{R_{e}}
$$

or equivalently by

$$
-\frac{\Delta \ln \tau}{\Delta \ln R_{e}}=1
$$

For the case shown in Fig. $3,-\frac{\Delta R_{e}}{R_{e}}=\frac{3.4}{12.9}=0.26$ whereas $\frac{\Delta \tau}{\tau}=\frac{1.0}{13.4}=0.07$, indicating that the changes in optical depth were smaller than predicted by the changes in droplet effective radius had 
cloud liquid water remained constant. This result, however, is tenuous given the range of optical depths for both the contaminated and uncontaminated clouds.

In order to extract the changes in visible optical depths for the polluted clouds from the natural variability, which is often much larger than the changes, many segments of ship tracks, like the example shown in Figs. 2 and 3, were analyzed. The number of tracks logged for analysis are given in Table 1 . Only about $20 \%$ of the tracks produced segments for which comparisons of contaminated and nearby uncontaminated clouds could be made. In most of the cases, the tracks appeared in broken cloud systems for which too few pixels were overcast by cloud, thereby preventing retrievals of cloud properties. In some cases, adjacent tracks and track crossings were so complex that the automated routine for finding the tracks failed because it selected for the uncontaminated clouds pixels in adjacent tracks that were, in fact, contaminated. As mentioned earlier, all results were visually screened to ensure that failures of the automated track identification scheme were not included in the comparisons.

Clearly, the number of segments that were successfully analyzed was determined in part by the choice of segment and domain size. Ideally, contaminated clouds should be compared with nearby clouds that are in every way identical except for the effects of the added particles from the ship exhaust. To determine a suitable domain size, autocorrelation functions were calculated for each cloud property using randomly selected scan line segments in which adjacent pixels were overcast by low-level clouds from the same layer. Segments selected for these calculations had minimum lengths of 100 pixels. Similarly, autocorrelation functions were calculated for individual scan spot positions along the scan line for which all pixels at the same position in adjacent scan 
lines were overcast by clouds in the same layer for at least 100 consecutive lines. The autocorrelation length obtained for the $0.64-\mu \mathrm{m}$ optical depth was about $5 \mathrm{~km}$. The lengths for the droplet effective radius and cloud emission temperature were $10 \mathrm{~km}$. These results suggested that the properties of the contaminated clouds could be compared only with those of clouds a very short distance away. Even though the selection of contaminated and uncontaminated clouds by the automated scheme appeared to work, as shown in Fig. 1, as a precaution, the selection of the uncontaminated clouds for comparison was restricted to being greater than about $10 \mathrm{~km}$ from the location of the polluted pixels, as determined by the straight lines joining the manually logged points. Consequently, the uncontaminated clouds selected for comparison could not be taken as being truly identical to those contaminated. As a result, a large ensemble of cases was needed to detect the changes in visible optical depths in face of the large pixel-scale variability. Since the autocorrelation lengths for the cloud properties were rather short $(<10 \mathrm{~km})$, each segment $(\sim 30$ $\mathrm{km}$ ) that successfully produced a comparison was taken to provide an independent estimate of the indirect effect. Analyses were performed using domain sizes of 15, 50, and $100 \mathrm{~km}$ on either side of the tracks. Results for the different domain sizes were statistically identical.

For the July 1999 NOAA-14 overpasses, 452 track segments produced successful comparisons between polluted and nearby unpolluted clouds. Figure 4 shows the distribution of cloud emission temperatures, droplet effective radii, and optical depths for overcast ship track pixels and for the nearby pixels overcast by uncontaminated clouds. The distributions were obtained for a domain of $15 \mathrm{~km}$ on either side of the ship track. The distributions for the contaminated and uncontaminated clouds are remarkably similar. The distributions reflect typical emission temperatures, droplet effective radii, and visible optical depths for marine stratus off the 
west coast of the U.S. Of course, pixels identified as contaminated had, on average, droplet effective radii that were between 2 and $3 \mu \mathrm{m}$ smaller than those of the nearby uncontaminated clouds. Ackerman et al. (2000) reported an average change of $3 \mu \mathrm{m}$ for the aircraft observations collected during the MAST experiment. There were no obvious shifts in the distributions of cloud emission temperatures and optical depths. The natural variability in cloud properties, particularly the variability in optical depth at the $1-\mathrm{km}$ scale, masks the indirect effect.

Figure 5 shows changes in cloud emission temperatures, droplet effective radii, and visible optical depths for the same 452 track segments used to produce the results shown in Fig. 4 . The values given in the figure are mean differences and an estimate for two standard deviations in the ensemble mean assuming that each of the segments provided an independent estimate of the change. The assumption that the segments are statistically independent seems justified given the short autocorrelation lengths for the cloud properties. With the exception of the difference in effective radii for the contaminated and uncontaminated pixels, the differences appear to be normally distributed. Consequently, the estimates of the two standard deviations in the ensemble means approximate a $90 \%$ confidence interval for the mean. In addition, since uncontaminated clouds reside on either side of the track, differences in the properties for the uncontaminated clouds provide a measure of the uncertainty to be expected for the difference in the properties of the contaminated and uncontaminated clouds. The results in Fig. 5 indicate that differences in cloud emission temperature, droplet effective radius, and visible optical depth were zero for the uncontaminated clouds. The contaminated clouds had effective droplet radii that were approximately $2 \mu \mathrm{m}$ smaller than their uncontaminated counterparts. The difference was, of course, significant. The changes in droplet effective radius and the associated changes in the 
3.7- $\mu \mathrm{m}$ radiance were used to identify the ship tracks. The visible optical depths for the contaminated clouds were slightly higher than those for the uncontaminated clouds, but the changes were at the detection limit. Changes in emission temperature were insignificant. The lack of change in emission temperature suggests that an increase in cloud top altitude, as proposed by Pincus and Baker (1994), is not evident.

By selecting segments for which the change in the droplet effective radius was greater than a certain value, the magnitude of the indirect effect was enhanced. Figure 6 shows distributions for the cases in which changes in the effective radius were greater than $2 \mu \mathrm{m}$. Of the segments that produced successful comparisons, about half had changes in the droplet effective radius greater than $2 \mu \mathrm{m}$. Interestingly, these cases corresponded to clouds that had larger droplets, $R_{e}=13.5 \mu \mathrm{m}$, and smaller optical depths, $\tau=10.8$, than those for which any change could be detected, $R_{e}=12.0 \mu \mathrm{m}$ and $\tau=11.5$. The clouds that produced the largest changes were, on average, more susceptible to change, as discussed by Platnick and Twomey (1994).

With the change in effective radius set to be greater than $2 \mu \mathrm{m}$, noticeable differences begin to appear for the visible optical depths. Figure 7 shows distributions for differences in cloud emission temperature, effective droplet radius, and visible optical depth for the cases in which the change in the effective radius was greater than $2 \mu \mathrm{m}$. The results indicate that the change in droplet radius was statistically zero for the two sets of uncontaminated clouds, but of course, the difference was much larger between the contaminated and uncontaminated clouds. Likewise, the difference in optical depth was statistically zero for the two sets of uncontaminated 
clouds, but the average difference between the contaminated and uncontaminated pixels was close to unity, and differed significantly from zero, indicating the existence of a definite indirect effect. As before, no change was detected in cloud emission temperature.

In order to compare the magnitude of the indirect effect in terms of the magnitude that would be expected if cloud liquid water remained constant, Figure 8 shows the distributions for $-\Delta \ln \tau / \Delta \ln R_{e}$. The values are compared with unity, the value expected for fixed cloud liquid water as noted in (3). Again, differences between the two sets of uncontaminated pixels were near zero, but between the contaminated and uncontaminated pixels, the differences differed substantially from zero, however, the differences were also substantially less than unity. The average changes indicate that the fractional change in the visible optical depth is only about half that expected for the fractional change in the droplet effective radius assuming cloud liquid water amount remained constant.

The results in Fig. 8 might explain the conflicting results mentioned earlier in which ship tracks exhibited both an increase in cloud water (Radke et al. 1989; Platnick and Twomey, 1994; Taylor et al. 2000) and a decrease (Platnick et al. 2000). 16\% of the tracks gave rise to values of $-\Delta \ln \tau / \Delta \ln R_{e}$ that were greater than unity, thereby suggesting that the polluted clouds had larger liquid water amounts. By far the majority, however, appeared to have reduced liquid water amounts.

Of course, the polluted clouds which had larger water amounts, also had large changes in visible optical depths. In $72 \%$ of these cases the change in the visible optical depth was larger 
than the standard deviation of the pixel-scale optical depths within the 30-km segment.

Examination of images constructed from the $0.64-\mu \mathrm{m}$ reflectances and $3.7-\mu \mathrm{m}$ radiances suggests that the ratio of the change in the optical depth or droplet effective radius to the pixel-scale standard deviation, which is a measure of signal to noise, of order 1:1 is sufficient for the track to become barely detectable in the images. Typical values of this ratio for the droplet effective radius were $3-5$ for the tracks analyzed in this study. In only $17 \%$ of the cases, the ratio for the optical depth exceeded 1:1. Furthermore, unlike the changes in droplet radii, which maintained large signal to noise ratios for many connected 30-km segments, large changes in optical depths were typically observed in a single segment, and rarely in as many as two connected segments. Consequently, few, if any of the tracks studied here, would have been identified in images constructed from reflected sunlight at visible wavelengths.

This result may provide a partial explanation of why Platnick and Twomey (1994) found that when polluted by ships, clouds had more liquid water than their unpolluted counterparts. Platnick and Twomey used visible images to select the tracks and to separate polluted clouds from nearby unpolluted clouds. By relying on visible reflectances to identify tracks, they may have selected cases for which liquid water amounts in the polluted clouds were larger than those of the surrounding uncontaminated clouds. For the $17 \%$ of the cases in which the ratio of the change in the optical depth to the pixel-scale standard deviation of optical depth exceeded $1: 1,67 \%$ also had polluted clouds with liquid water amounts that exceeded those of the nearby uncontaminated clouds. Another possible explanation, however, is that Platnick and Twomey used visual inspection of the imagery to select pixels for analysis. All pixels analyzed were assumed to be overcast and no allowance was made for pixels being only partially cloud covered. Consequently, 
they may have found larger optical depths for the polluted clouds because the pixels associated with the ship tracks had larger cloud amounts when compared with the uncontaminated pixels that were chosen for comparison. In the current study, some tracks became detectable in the $0.64-\mu \mathrm{m}$ imagery when the tracks broke away from a layer of extensive overcast into either a system of broken clouds or a cloud-free region. Such tracks often failed to become part of the analyzed data, however, because even though sufficient numbers of pixels were found to be overcast within the track, a like number of pixels overcast by cloud in the vicinity of the track could not be found.

Han et al. (2000) also report a trend to less liquid water in clouds with larger droplet numbers. They base their results on monthly observations of pixel scale cloud optical depths and droplet effective radii for $2.5^{\circ} \times 2.5^{\circ}$ latitude-longitude regions. By regressing spherical albedos for clouds, derived from visible optical depths, to the column number of droplets, derived from visible optical depths and effective droplet radii, they obtain a slope which is smaller than that predicted if cloud liquid water was constant in the region. While qualitatively consistent with the current findings, how trends derived from spatial and temporal changes in cloud properties, as analyzed by Han et al., correspond to changes due to increased particle concentrations, as studied here, is unclear. In addition, the Han et al. results might also be subject to the analysis method. The results depend on the ISCCP threshold method for identifying overcast pixels. No allowance was made for pixels being partially cloud covered nor for variations in cloud emission temperatures that fell within the broad ranges employed by ISCCP. Some of the relationship between spherical albedo and the column number of droplets may have arisen through changes in cloud amount or changes in cloud thickness, as opposed to changes in droplet concentrations. 
A possible explanation for the indirect effect being smaller than that expected for fixed liquid water amount is that the particles which provide $\mathrm{CCN}$ for the increase in droplet number absorb sunlight. Table 2 gives results obtained using the Eddington approximation to calculate spherical albedos at visible wavelengths. The calculations were performed for the cases in which the change in effective radius was greater than $2 \mu \mathrm{m}$. They include the spherical albedo for 1) the average conditions for the uncontaminated clouds, as given in Fig. 5; 2) the average for the polluted clouds, 3) a composite cloud which has the same liquid water amount as the uncontaminated cloud but the added droplets have a low single scattering albedo, and 4) two composite clouds in which aerosols with different single-scattering albedos are mixed with the cloud droplets. Except for the average polluted cloud, the total optical depths of the mixed aerosol cloud systems were adjusted to produce the same cloud liquid water amount as inferred for the unpolluted cloud. The results indicate that if liquid water amount remained constant, then in order to produce the observed changes in cloud reflectance, the single scattering albedo of the new droplets in the contaminated clouds would have to be 0.985 . This low value represents substantial absorption. In the case of added aerosols, the optical depths of absorbing aerosols that would have to be mixed in the cloud in order to produce the observed changes ranges from $0.2-$ 0.6. The results given in the table include the effects of scattering and absorption by the aerosol as well as by the cloud. The aerosol model used in these calculations was the average continental aerosol described by Hess et al. (1998). It has a single-scattering albedo of about 0.9 and an asymmetry parameter of about 0.7 at a relative humidity of $70 \%$. Results are also given assuming that the absorption is twice that of the average continental aerosol. According to Hobbs et al. (2000), ships generate $10^{16}$ particles per second. If these particles are distributed over a 1-km swath, so that they become readily detectable as a ship track in the 1-km AVHRR imagery, and if 
ship speed is $5 \mathrm{~m} \mathrm{sec}^{-1}$, then near the ship, the tracks have a particle density of $\sim 2 \times 10^{8} \mathrm{~cm}^{-2}$. All but a few percent by number have radii in the $0.01-0.1 \mu \mathrm{m}$ range. According to the data in Hess et al. (1998) the cross section for an average continental aerosol particle at $80 \%$ relative humidity is approximately $5 \times 10^{-11} \mathrm{~cm}^{2}$, which gives an optical depth for the track of 0.01 , and that for an urban particle is $2 \times 10^{-11} \mathrm{~cm}^{2}$, for an optical depth of 0.004 . The urban plume is more like that of the ship plumes. For urban plumes, the number of particles with radii in the $0.01-0.1 \mu \mathrm{m}$ range is almost an order of magnitude larger than that for particles at larger sizes, while for the average continental aerosol, the number in the smaller range is approximately equal to that in the larger range. Based on these estimates of particle cross sections and number densities, the potential aerosol burden produced by ships is at least one and possibly two orders of magnitude too small to explain the less than expected response of the cloud optical depths observed in ship tracks. Other mechanisms appear necessary to explain the smaller than expected indirect effect.

Another explanation for the reduced indirect effect is a loss of cloud water in the polluted clouds. Since cloud liquid water is proportional to the product of the optical depth and effective radius, the changes shown in Fig. 7 suggest that for the clouds that had relatively large changes in effective radius, the remaining cloud water was $80-85 \%$ of the initial cloud water. Fig. 7 shows no differences in the cloud emission temperature between the contaminated and nearby uncontaminated clouds, suggesting that cloud boundaries, at least the top boundary, did not move. Such a loss in cloud liquid water might result from the additional heating caused by the addition of absorbing particles. The heating evaporates some of the droplets and it reduces the intensity of the convection thereby reducing the flux of moisture into the cloud that is required for its maintenance (Ackerman et al. 2000). One notes that in the earliest known study of the indirect 
effect, the contaminated clouds likewise had liquid water contents that were about $85 \%$ of their uncontaminated counterparts (Warner and Twomey, 1967). Also, of the 69 ship tracks for which aircraft observations were compiled during the MAST experiment, the average reduction in liquid water concentration was $17 \%$ (Ackerman et al., 2000).

\section{Conclusions}

Analysis of sunlight reflected by low-level clouds off the west coast of the U.S. revealed that clouds polluted by plumes from underlying ships generally had higher reflectivities at visible wavelengths than their nearby unpolluted counterparts. This enhancement, however, was difficult to detect given the variability in reflectivities at visible wavelengths for overcast marine stratus. The enhancement was statistically significant for an ensemble of cases in which the change in droplet effective radius was greater than $2 \mu \mathrm{m}$. Interestingly, the clouds that exhibited the largest changes were those for which the optical depths were, on average, smaller and the droplet effective radii larger. They were thus more susceptible to change as suggested by Platnick and Twomey (1994).

There was no evidence for a change in the altitude of the upper cloud boundary between the polluted and unpolluted clouds. The lack of a change in the upper cloud boundary suggests that cloud thickening, like that proposed by Pincus and Baker (1994), is not observed. 
For the cases in which the change in the droplet effective radius was greater than $2 \mu \mathrm{m}$, the fractional change in the visible optical depth was only about half the value expected had cloud liquid water remained constant. Factors which may dampen the change in reflectances at visible wavlengths are increased absorption of sunlight in the polluted clouds and loss of liquid water. Results of calculations using the Eddington approximation suggest that the amount of absorption that needs to be added to the cloud in order to reduce the change in visible reflectance, while keeping cloud liquid water constant, is excessive. The amount is equivalent to absorbing aerosol layers with optical depths of $0.2-0.6$ filling the cloud layer and covering a domain the width typically observed for ship tracks, i.e. several kilometers. These aerosol burdens are at least an order of magnitude larger than burdens produced by ships. Equivalently, of the liquid water in the uncontaminated clouds, an average of $15-20 \%$ disappears when the clouds become contaminated. It is suggested that both absorption by the polluting particles and loss of liquid water are occurring. As Ackerman et al. (2000) suggested, added absorption within low-level marine clouds evaporates some of the cloud water and it reduces the intensity of convection in the boundary layer. The reduction of convection reduces the flux of water vapor into the polluted cloud compared with the flux of vapor into the neighboring unpolluted clouds. Absorption, evaporation, and differences in vapor fluxes lead to the loss of water in the polluted clouds. 
Acknowledgment

This work was supported through NASA's Global Aerosol Climatology Project, NASA Grant NAG5-7686. The data used in the analysis was collected by the Oregon Earth Watch Facility at Oregon State University. We thank Jason Cheek and Mark Matheson for help with the analysis of the satellite observations. We also thank Andy Ackerman and Steve Platnick for their many useful suggestions and comments on this work.

\section{References}

Ackerman, A.S., O.B. Toon, and P.V. Hobbs, 1995: Numerical modeling of ship tracks produced by injection of cloud condensation nuclei into marine stratiform clouds. J. Geophys. Res., 100, 7121-7133.

Ackerman, A.S., O.B. Toon, D.E. Stevens, A.J. Heymsfield, V. Ramanathan, and E.J. Welton, 2000: Reduction of tropical cloudiness by soot. Science, 288, 1042-1047.

Albrecht, B.A., 1989: Aerosols, cloud microphysics and fractional cloudiness. Science, 245, 1227-1230.

Coakley, J.A., Jr., R.L. Bernstein, and P.A. Durkee, 1987: Effect of ship-stack effluents on cloud reflectivity. Science, 237, 1020-1022. 
Durkee, P.A., K.J. Noone, and R.T. Bluth, 2000: The Monterey Area Ship Track Experiment. J. Atmos. Sci., 57, 2523-2541.

Han, Q., W.B. Rossow, and A.A. Lacis, 1994: Near-global survey of effective droplet radii in liquid water clouds using ISCCP data. J. Climate, 7, 465-497.

Han, Q., W.B. Rossow, J. Chou, and R.M. Welch, 2000: Near-global survey of cloud column susceptibilities using ISCCP data. Geophys. Res. Letts. 19, 3221-3224.

Hansen, J., M. Sato, and R. Ruedy, 1997: Radiative forcing and climate response. J. Geophys. Res., 102, 6831-6864.

Hess, M., P. Koepke, and I. Schult, 1998: Optical properties of aerosols and clouds: The software package OPAC. Bull. Amer. Meteor. Soc. 79, 831-844.

Kratz, D.P., 1995: The correlated $k$-distribution technique as applied to the AVHRR channels. $J$. Quant. Spectrosc. Radiat. Transfer, 53, 501-517.

Kuji, M., T. Hyasaka, N. Kikuchi, T. Nakajima, and M. Tanaka, 2000: The retrieval of effective particle radius and liquid water path of low-level marine clouds from NOAA AVHRR data. $J$. Appl. Meteor., 39, 999-1016. 
Lauritsen, L., G.J. Nelson, and F.W. Porto, 1979: Data Extraction and Calibration of TIROSN/NOAA Radiometers. NOAA Technical Memorandum NESS-107, U.S. Department of Commerce, 73pp. [Available from NOAA/NESDIS, Room 703, World Weather Building, Washington, D.C. 20233.]

Loeb, N.G., and J.A. Coakley, Jr., 1998: Inference of marine stratus cloud optical depths from satellite measurements: Does 1-D theory apply? J. Climate, 11, 215-233.

Lohmann U., and J. Feichter, 1997: Impact of sulfate aerosols on albedo and lifetime of clouds: A sensitivity study with the ECHAM GCM. J. Geophys. Res., 102, 13,685-13,700.

Lohmann, U., J. Feichter, J. Penner, and R. Leaitch, 2000: Indirect effect of sulfate and carbonaceous aerosols: A mechanistic treatment. J. Geophys. Res., 105, 12,193-12,206.

Nakajima, T., M.D. King, J.D. Spinhirne, and L.F. Radke, 1991: Determination of the optical thickness and effective particle radius of clouds from reflected solar radiation measurements. Part II: Marine stratocumulus observations. J. Atmos. Sci. 48, 728-750.

Nakajima T.Y., and T. Nakajima, 1995: Wide-area determination of cloud microphysical properties from AVHRR measurements for FIRE and ASTEX regions. J. Atmos. Sci. 52, 4043-4059. 
Pincus, R., and M.B. Baker, 1994: Effect of precipitation on the albedo susceptibility of clouds in the marine boundary layer. Nature, 312, 250-252.

Platnick, S., and S. Twomey, 1994: Determining the susceptibility of cloud albedo to changes in droplet concentration with the Advanced Very High Resolution Radiometer. J. Appl. Meteor., 33, 334-347.

Platnick, S., and F.P.J. Valero, 1995: A validation of a satellite cloud retrieval during ASTEX, J. Atmos. Sci., 52, 2985-3001.

Platnick, S., P.A. Durkee, K. Nielson, J.P. Taylor, S-C. Tsay, M.D. King, R.J. Ferek, P.V. Hobbs, and J.W. Rottman, 2000: The role of background cloud microphysics in the radiative formation of ship tracks. J. Atmos. Sci. 57, 2607-2624.

Radke, L.F., J.A. Coakley, Jr., and M.D. King, 1989: Direct and remote sensing observations of the effects of ships on clouds. Science, 246, 1146-1149.

Rotstayn, L.D., 1999: Indirect forcing by anthropogenic aerosols: A global climate model calculation of the effective-radius and cloud-lifetime effects. J. Geophys. Res., 104, 93699380.

Saunders, R.W. and K.T. Kriebel, 1988: An improved method for detecting clear sky and cloudy radiances from AVHRR data. Int. J. Remote Sens. 9, 123-150. 
Stamnes, K., S.-C. Tsay, W. Wiscombe, and K. Jayaweera, 1988: A numerically stable algorithm for discrete-ordinate-method radiative transfer in multiple scattering and emitting layered media. Appl. Opt., 27, 2502-2509.

Taylor, J.P., M.D. Glew, J.A. Coakley, Jr., W.R. Tahnk, S. Platnick, P.V. Hobbs, and R.J. Ferek, 2000: Effects of aerosols on the radiative properties of clouds. J. Atmos. Sci., 57, 26562670.

Twomey, S., 1977: The influence of pollution on the shortwave albedo of clouds. J. Atmos. Sci., 34, 1149-1152.

Tahnk, W.R., and J.A. Coakley, Jr., 2000a: Improved calibration coefficients for NOAA-14 AVHRR visible and near-IR channels. Int. J. Remote Sens. (in press).

Tahnk, W.R., and J.A. Coakley, Jr., 2000b: Further improvements to calibration coefficients for NOAA-14 AVHRR channels 1 and 2. Int. J. Remote Sens. (submitted for publication).

Warner, J. and S. Twomey 1967: The production of cloud nuclei by cane fires and the effect on cloud droplet concentration. J. Atmos. Sci., 24, 704-706. 
Figure 1. Images constructed from $0.64-\mu \mathrm{m}$ reflectances and $3.7-\mu \mathrm{m}$ radiances showing portions of three ship tracks with their associated domains. The ship track being analyzed is identified by the points and adjoining lines in the 3.7- $\mu \mathrm{m}$ image. The points and lines represent the manual location of the track. The highlighted pixels in the 3.7- $\mu \mathrm{m}$ image were selected as contaminated and uncontaminated by the automated routine. The box shows the $30-\mathrm{km}$ segment for which results are presented in Figs. 2 and 3. The dark boundaries outline the domain from which uncontaminated pixels are drawn. In this example, the domain is approximately $30 \mathrm{~km}$ on either side of the track.

Figure 2. Retrieved $0.64-\mu \mathrm{m}$ optical depths and droplet effective radii and the corresponding $0.64-\mu \mathrm{m}$ reflectances and 3.7- $\mu \mathrm{m}$ radiances. The observations are for the track segment shown in Fig. 1. The contaminated pixels are identified by $\Delta$; the uncontaminated pixels are identified by $\times$. The solar zenith angle, $\theta_{0}$, satellite zenith angle, $\theta$, relative azimuth angle, $\phi$, cloud emission temperature, $T_{C}$, and surface temperature, $T_{S}$, are the average values for the contaminated and uncontaminated pixels in the segment.

Figure 3. 1-km pixel-scale $0.64-\mu \mathrm{m}$ optical depths, droplet effective radii, and cloud emission temperatures for the track segment shown in Fig. 1. The contaminated pixels are indicated by $\Delta$; the uncontaminated pixels are indicated by $\times$. Means and two standard deviations on either side of the mean are represented by the error bars and associated symbol. 
Figure 4. Average optical depths and droplet effective radii for contaminated (solid line) and uncontaminated (dashed line) pixels taken from 30-km track segments. The number of track segments, means and standard deviations of the distributions are given.

Figure 5. Differences in average optical depths and effective droplet radii, contaminated uncontaminated, (solid line), for 30-km track segments, and the differences between the uncontaminated pixels on either side of the ship track (dashed line). The number of track segments, means and estimates of two standard deviations for the ensemble means are given.

Figure 6. Same as Fig. 4 except for cases in which the average difference in the droplet effective radius, uncontaminated - contaminated, was greater than $2 \mu \mathrm{m}$.

Figure 7. Same as Fig. 5 except for cases in which the average difference in the droplet effective radius, uncontaminated - contaminated, was greater than $2 \mu \mathrm{m}$.

Figure 8. $-\Delta \ln \tau / \Delta \ln R_{e}$ for the 30-km ship track segments in which the average change in droplet effective radius, uncontaminated - contaminated, was greater than $2 \mu \mathrm{m}$.

$-\Delta \ln \tau / \Delta \ln R_{e}=1$ if the cloud liquid water amount remains constant. The number of segments, means, and estimates of two standard deviations for the ensemble means are given. 
Table 1. Ship tracks analyzed, July 1999. Segments were approximately $30 \mathrm{~km}$ in length and the domain for the uncontaminated clouds was $15 \mathrm{~km}$ on either side of the track.

\begin{tabular}{|c|c|c|}
\hline Satellite & NOAA-14 & NOAA-12 \\
\hline Nominal Local time & 1600 & 0730 \\
\hline Ship tracks logged & 680 & 337 \\
\hline $\begin{array}{l}\text { Ship tracks producing } \\
\text { segments suitable for analysis }\end{array}$ & 136 & 42 \\
\hline Segments suitable for analysis & 452 & 133 \\
\hline
\end{tabular}


Table 2. Cloud and aerosol properties required to produce the same spherical albedos at visible wavelengths as the ship track. Values were obtained with the Eddington approximation.

\begin{tabular}{|c|c|c|c|c|c|c|c|c|}
\hline \multirow{2}{*}{$\begin{array}{l}\text { Cloud } \\
\text { System }\end{array}$} & \multicolumn{4}{|c|}{ Cloud Properties } & \multicolumn{3}{|c|}{ Added Aerosol or Cloud Water } & \multirow{2}{*}{$\begin{array}{c}\text { Spherical } \\
\text { Albedo }\end{array}$} \\
\hline & $\begin{array}{l}\text { Effective } \\
\text { Radius }\end{array}$ & $\begin{array}{l}\text { Optical } \\
\text { Depth }\end{array}$ & $\begin{array}{l}\text { Asymmetry } \\
\text { Parameter }\end{array}$ & $\begin{array}{c}\text { Single Scattering } \\
\text { Albedo }\end{array}$ & $\begin{array}{l}\text { Optical } \\
\text { Depth }\end{array}$ & $\begin{array}{l}\text { Asymmetry } \\
\text { Parameter }\end{array}$ & $\begin{array}{c}\text { Single Scattering } \\
\text { Albedo }\end{array}$ & \\
\hline $\begin{array}{l}\text { Marine } \\
\text { stratus }\end{array}$ & 13.5 & 10.8 & 0.861 & 1.000 & 0 & 0 & 0 & 0.530 \\
\hline Ship track & 10.2 & 11.7 & 0.856 & 1.000 & 0 & 0 & 0 & 0.558 \\
\hline $\begin{array}{l}\text { Absorbing } \\
\text { droplets } \\
\text { added }\end{array}$ & 10.2 & 10.8 & 0.856 & 1.000 & 3.5 & 0.856 & 0.985 & 0.558 \\
\hline $\begin{array}{l}\text { Aerosol } \\
\text { added }\end{array}$ & 10.2 & 13.7 & 0.856 & 1.000 & 0.6 & 0.678 & 0.899 & 0.560 \\
\hline $\begin{array}{l}\text { Aerosol } \\
\text { added }\end{array}$ & 10.2 & 14.0 & 0.856 & 1.000 & 0.2 & 0.678 & 0.8 & 0.555 \\
\hline
\end{tabular}


$0.64 \mu \mathrm{m}$

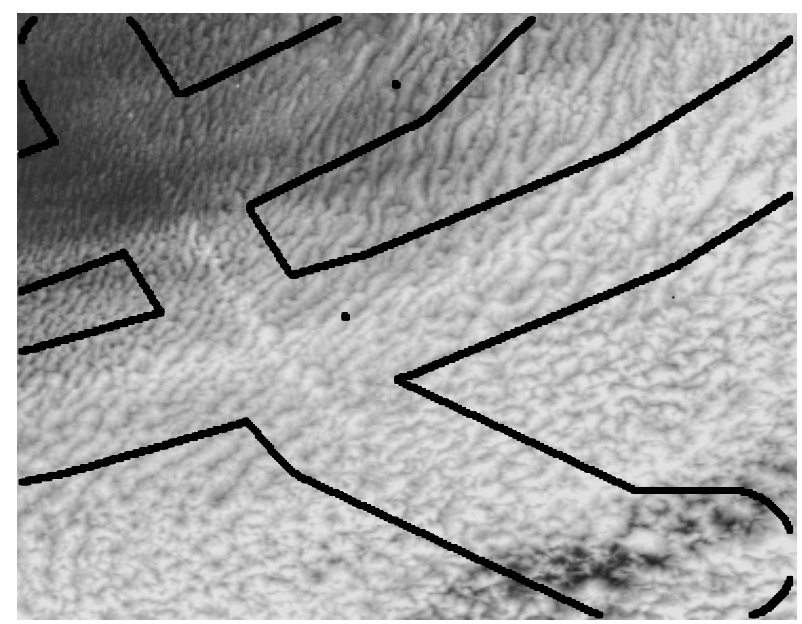

$3.7 \mu \mathrm{m}$
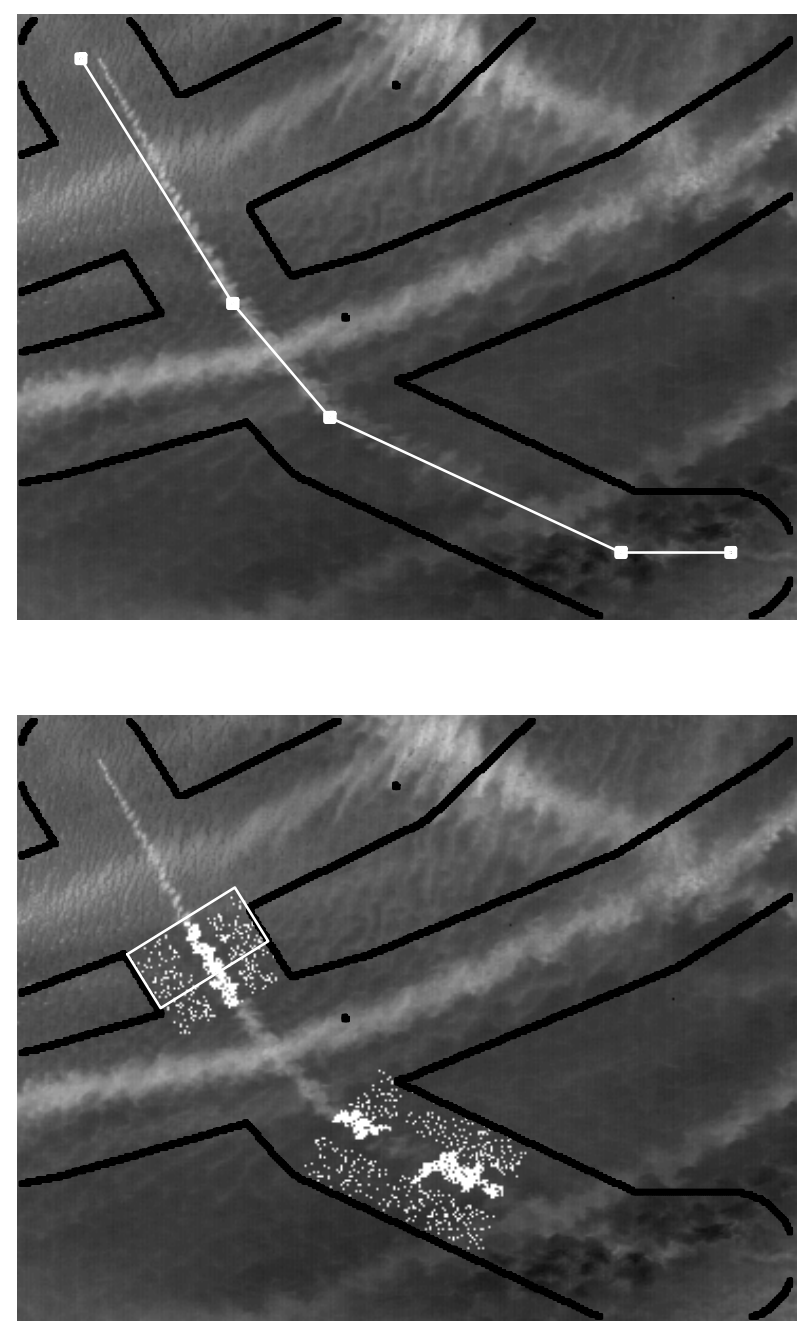

Figure 1. Images constructed from $0.64-\mu \mathrm{m}$ reflectances and 3.7- $\mu \mathrm{m}$ radiances showing portions of three ship tracks with their associated domains. The ship track being analyzed is identified by the points and adjoining lines in the $3.7-\mu \mathrm{m}$ image. The points and lines represent the manual location of the track. The highlighted pixels in the 3.7- $\mu \mathrm{m}$ image were selected as contaminated and uncontaminated by the automated routine. The box shows the 30$\mathrm{km}$ segment for which results are presented in Figs. 2 and 3. The dark boundaries outline the domain from which uncontaminated pixels are drawn. In this example, the domain is approximately $30 \mathrm{~km}$ on either side of the track. 


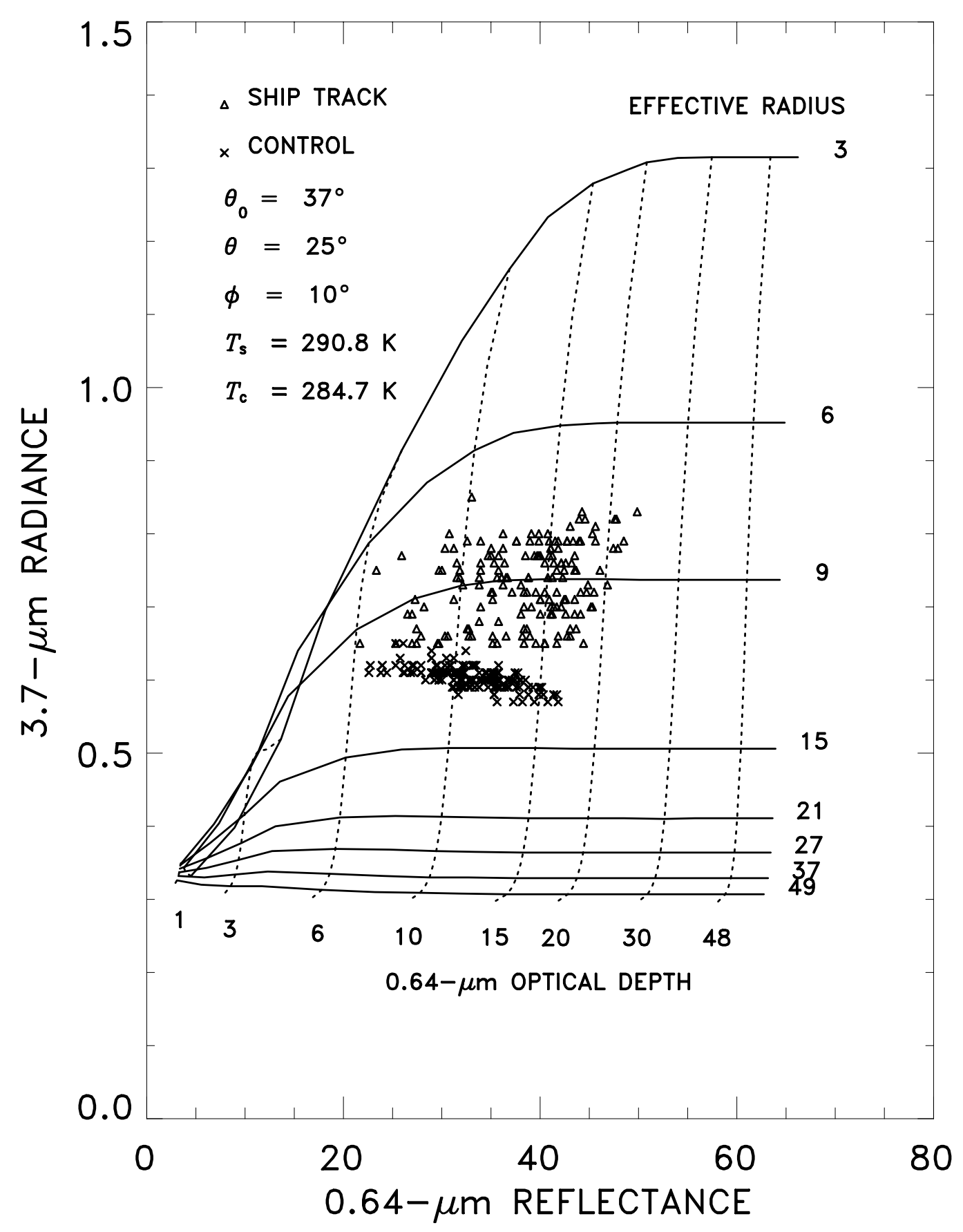

Figure 2. Retrieved $0.64-\mu \mathrm{m}$ optical depths and droplet effective radii and the corresponding $0.64-\mu \mathrm{m}$ reflectances and $3.7-\mu \mathrm{m}$ radiances. The observations are for the track segment shown in Fig. 1 . The contaminated pixels are identified by $\Delta$; the uncontaminated pixels are identified by $\times$. The solar zenith angle, $\theta_{0}$, satellite zenith angle, $\theta$, relative azimuth angle, $\phi$, cloud emission temperature, $T_{C}$, and surface temperature, $T_{S}$, are the average values for the contaminated and uncontaminated pixels in the segment. 

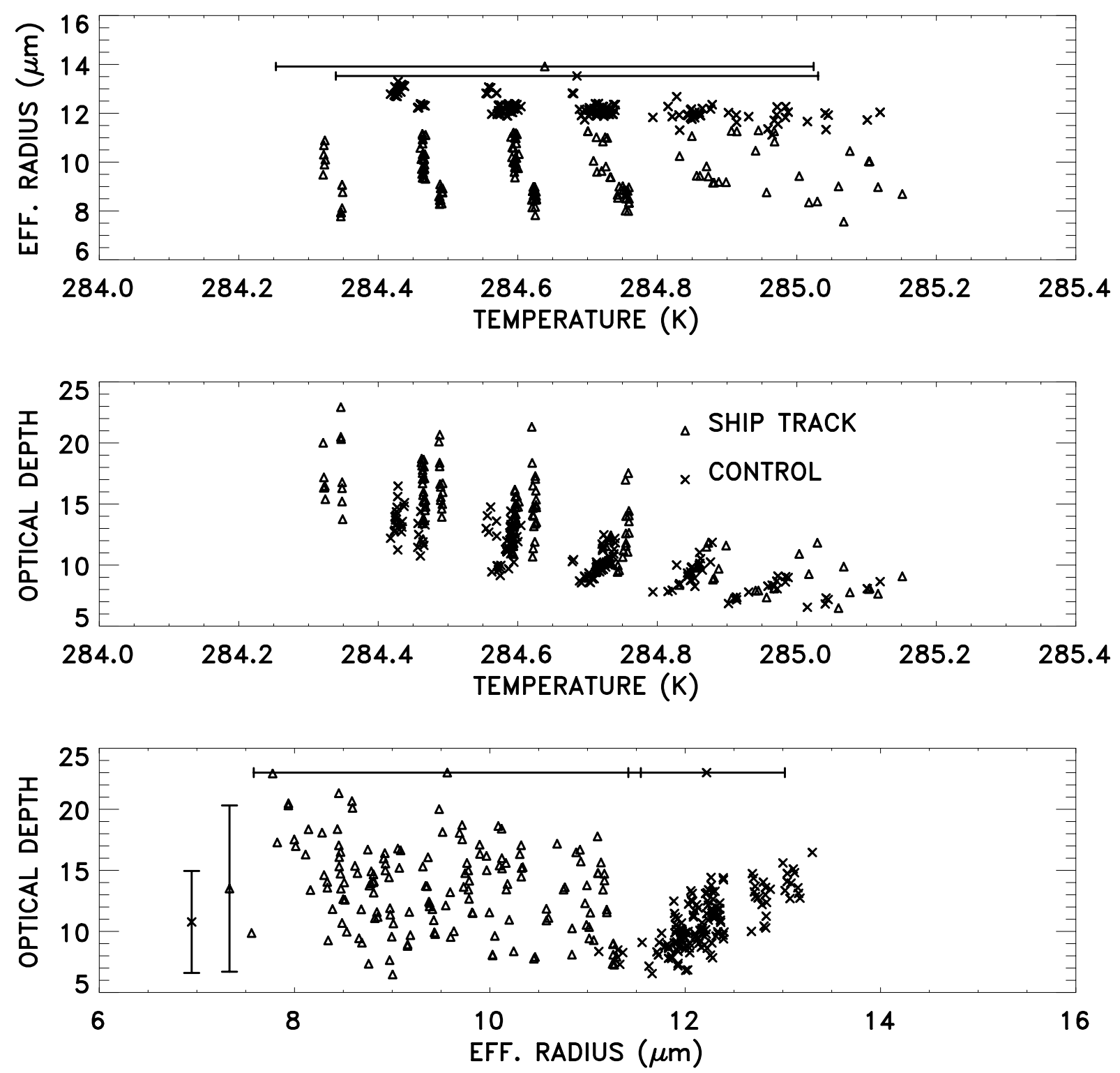

Figure 3. 1-km pixel-scale $0.64-\mu \mathrm{m}$ optical depths, droplet effective radii, and cloud emission temperatures for the track segment shown in Fig. 1. The contaminated pixels are indicated by $\Delta$; the uncontaminated pixels are indicated by $\times$. Means and two standard deviations on either side of the mean are represented by the error bars and associated symbol. 

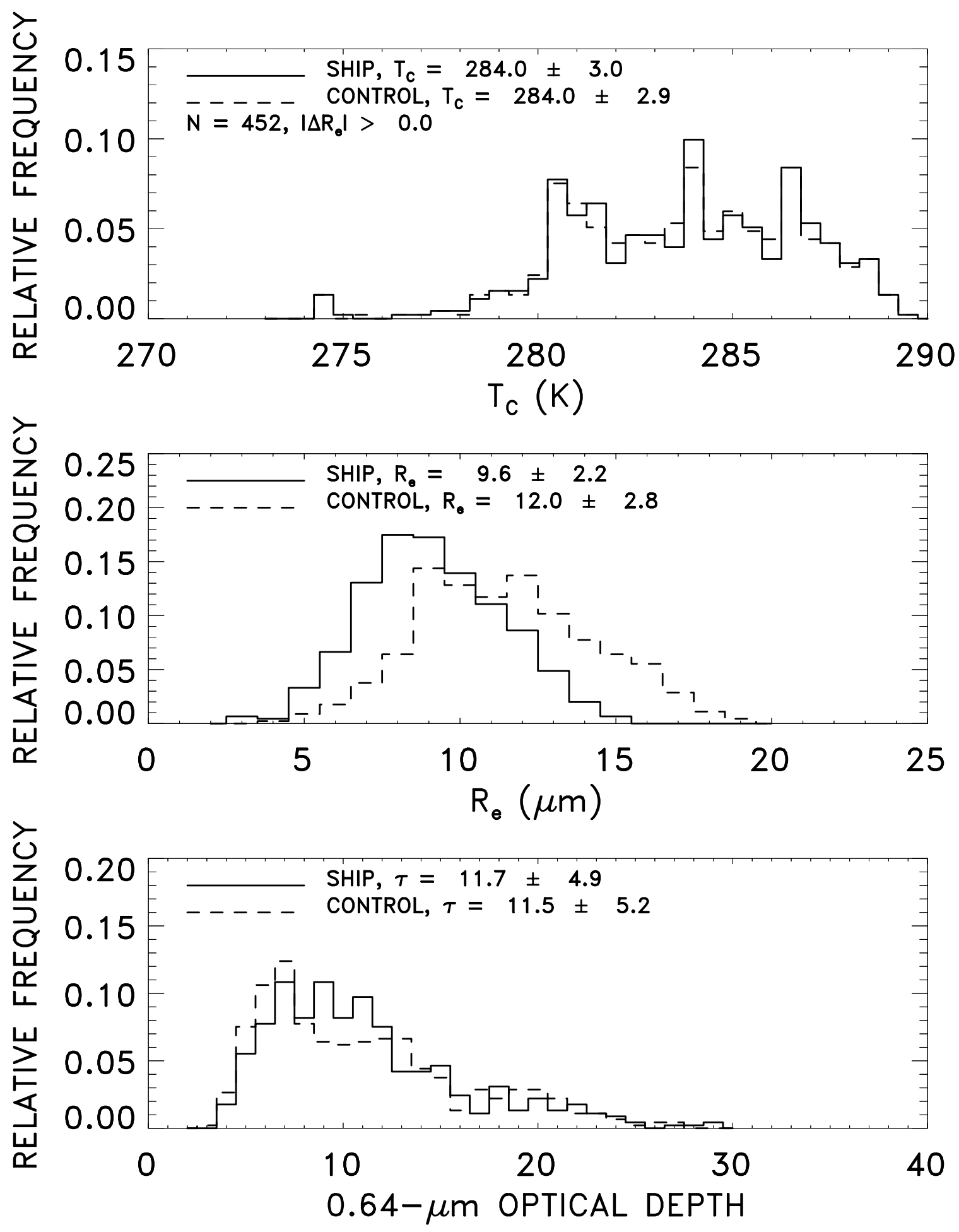

Figure 4. Average optical depths and droplet effective radii for contaminated (solid line) and uncontaminated (dashed line) pixels taken from 30-km track segments. The number of track segments, means and standard deviations of the distributions are given. 

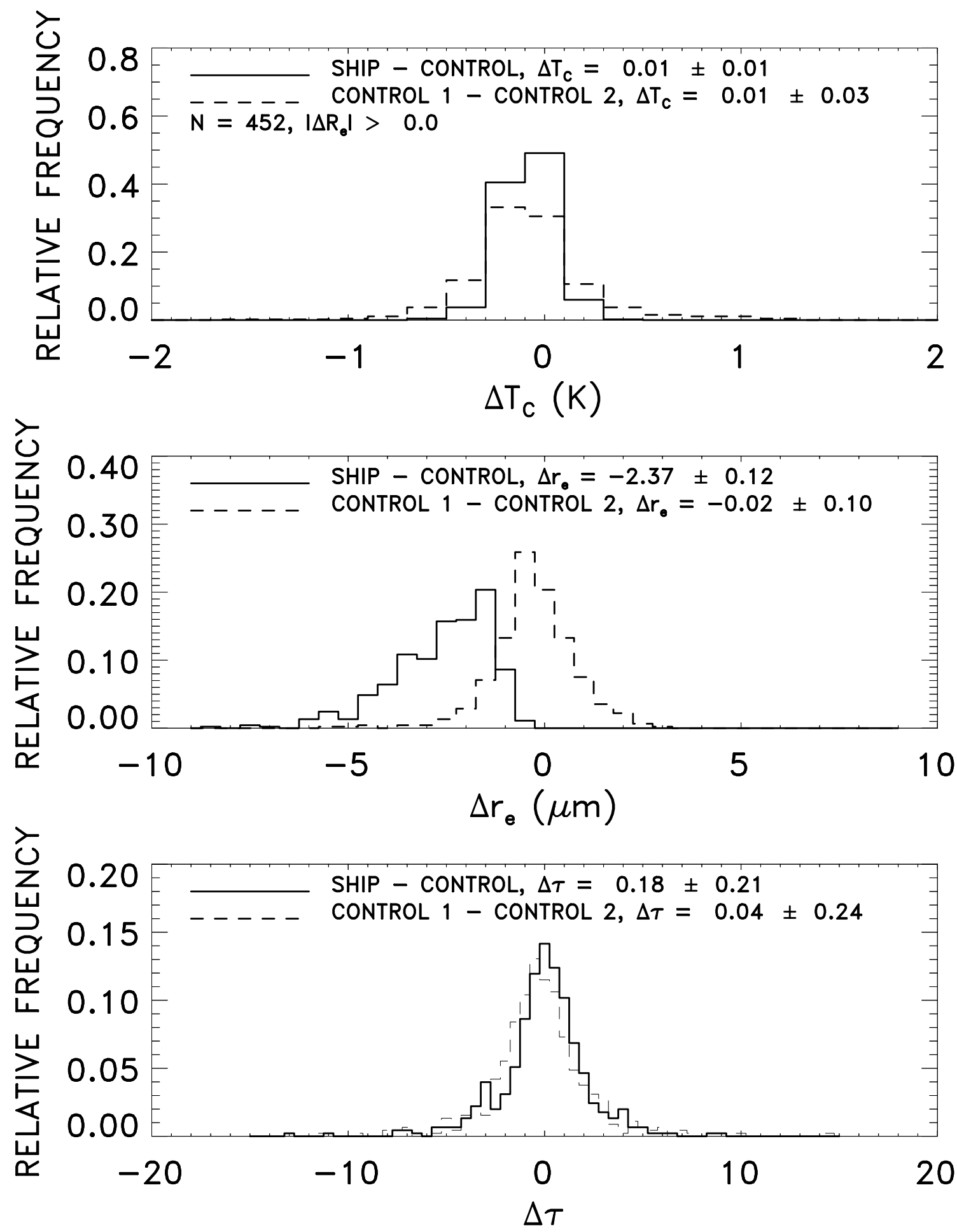

Figure 5. Differences in average optical depths and effective droplet radii, contaminated uncontaminated, (solid line), for 30-km track segments, and the differences between the uncontaminated pixels on either side of the ship track (dashed line). The number of track segments, means and estimates of two standard deviations for the ensemble means are given. 

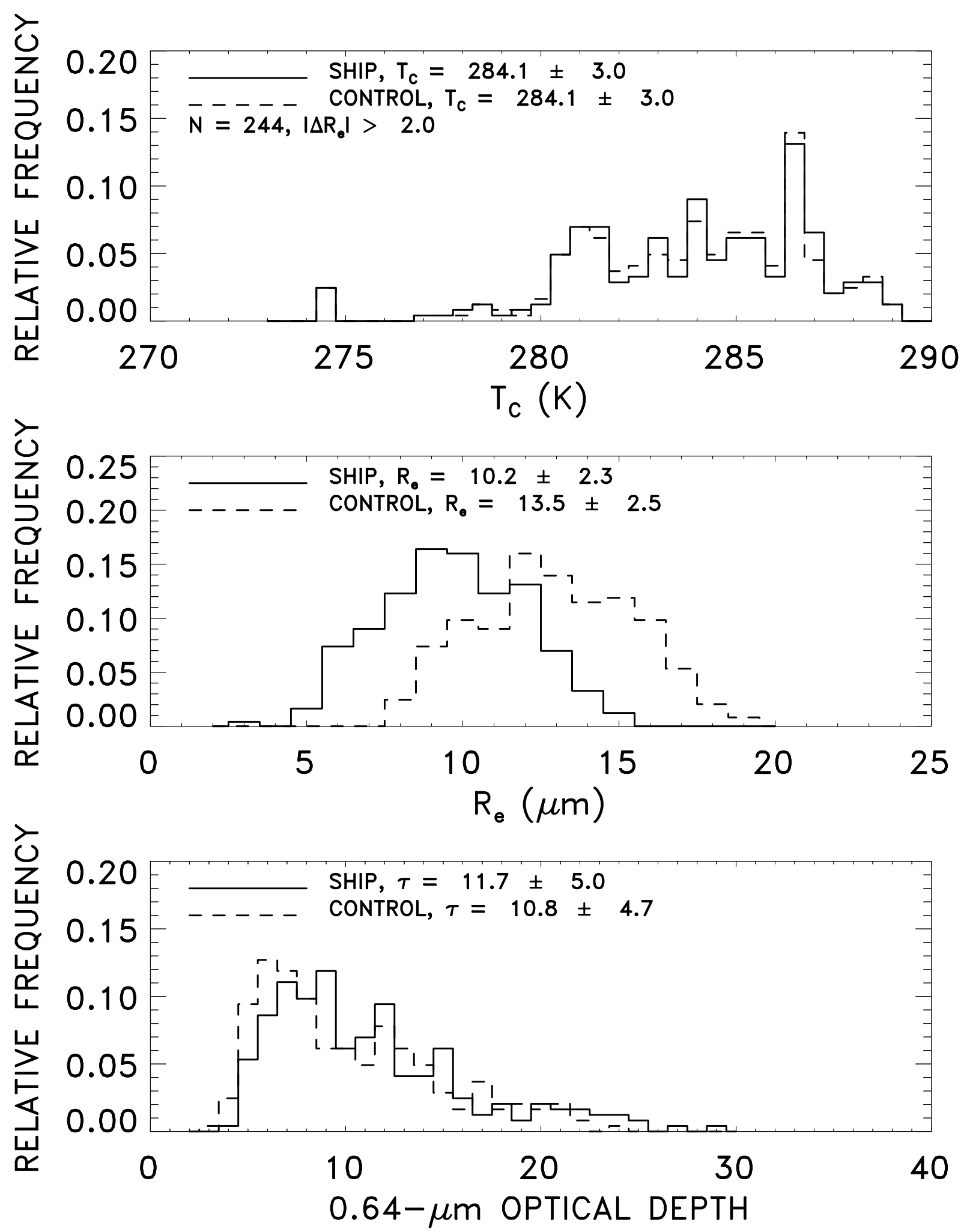

Figure 6. Same as Fig. 4 except for cases in which the average difference in the droplet effective radius, uncontaminated - contaminated, was greater than $2 \mu \mathrm{m}$. 

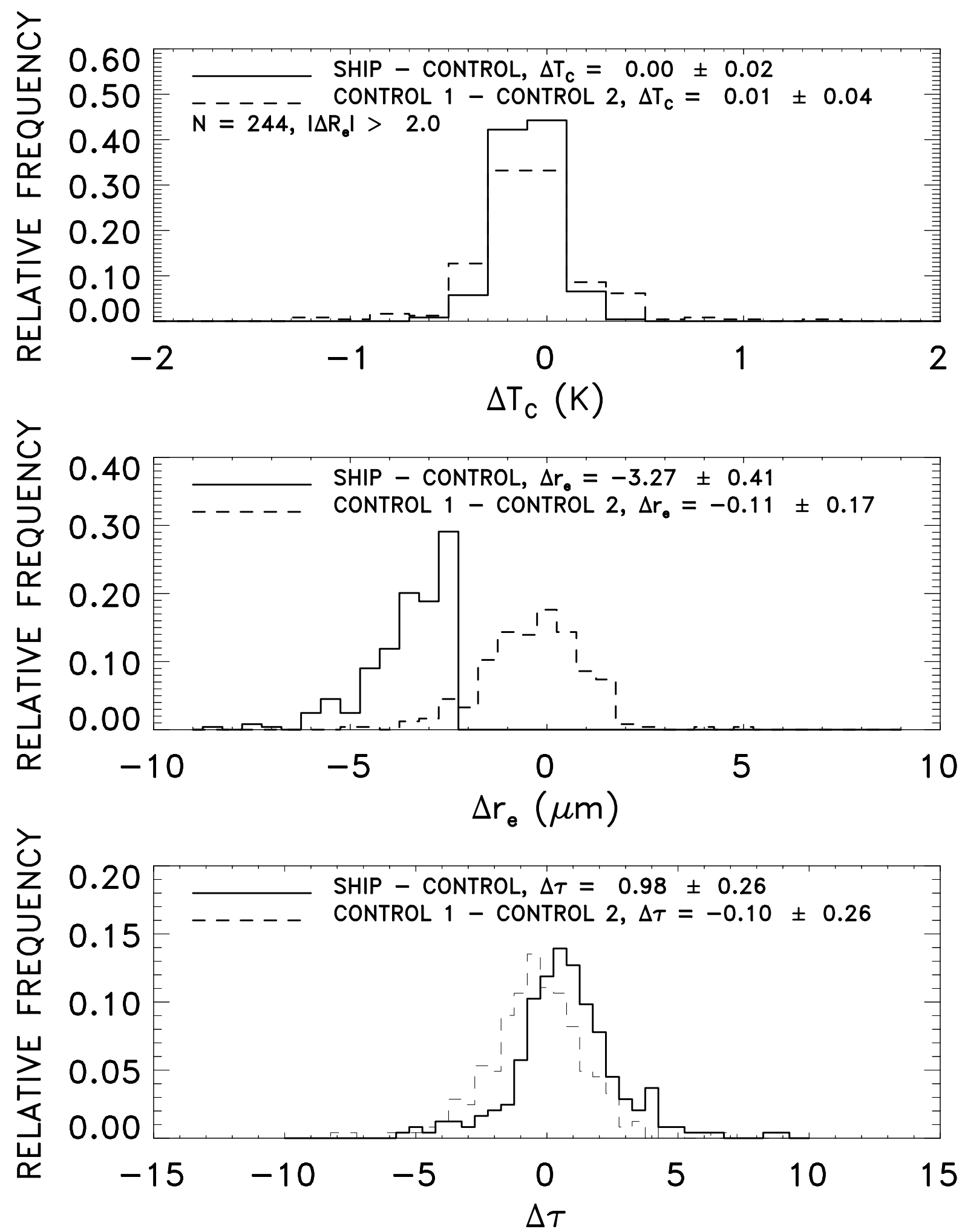

Figure 7. Same as Fig. 5 except for cases in which the average difference in the droplet effective radius, uncontaminated - contaminated, was greater than $2 \mu \mathrm{m}$. 


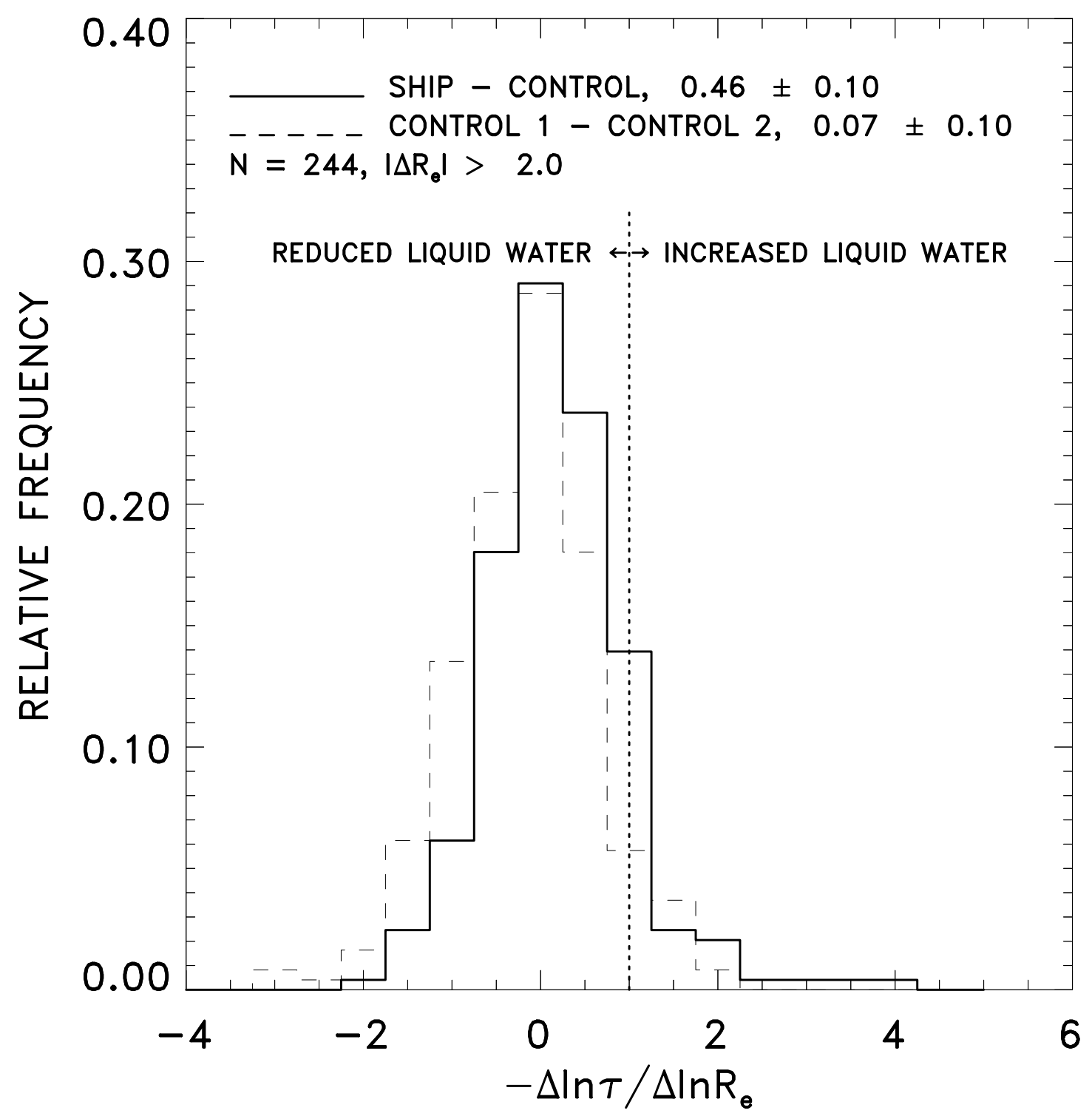

Figure 8. $-\Delta \ln \tau / \Delta \ln R_{e}$ for the 30-km ship track segments in which the average change in droplet effective radius, uncontaminated - contaminated, was greater than $2 \mu \mathrm{m}$. $-\Delta \ln \tau / \Delta \ln R_{e}=1$ if the cloud liquid water amount remains constant. The number of segments, means, and estimates of two standard deviations for the ensemble means are given. 